\title{
A Laser and Molecular Beam Mass Spectrometer Study of Low-Pressure Dimethyl Ether Flames
}

\author{
Andrew McIlroy, Toby D. Hain, Hope A. Michelsen \\ Sandia National Laboratories \\ Livermore, CA \\ Terrill A. Cool \\ Cornell University \\ Ithaca, NY
}

RECEIVED

FFR 232020

OSTI

Corresponding Author:

Andrew McIlroy

MS 9055, P.O. Box 969

The submitted manuscript has ben The submilted soantractor of the United authored by a contractor of the contraet. States Government under controt. Accordingly the United States non-exclusive, exnment retains a non-exclasive royalty-free license to publish of this produce the published form of this contribution, or allow others to do so, for United States Gorernment pur

Sandia National Laboratories poeses.

Livermore, CA 94551-0969

phone: (925) 294-3054

fax: (925) 294-2276

email: amcilr@sandia.gov

Colloquium: Reaction Kinetics of Combustion

Oral presentation preferred

Word count (MS Word):

\begin{tabular}{lr} 
Text: & 3800 \\
Table: & 100 \\
Figures: & 1400 \\
\hline Total: & 5300
\end{tabular}




\section{DISCLAIMER}

This report was prepared as an account of work sponsored by an agency of the United States Government. Neither the United States Government nor any agency thereof, nor any of their employees, make any warranty, express or implied, or assumes any legal liability or responsibility for the accuracy, completeness, or usefulness of any information, apparatus, product, or process disclosed, or represents that its use would not infringe privately owned rights. Reference herein to any specific commercial product, process, or service by trade name, trademark, manufacturer, or otherwise does not necessarily constitute or imply its endorsement, recommendation, or favoring by the United States Government or any agency thereof. The views and opinions of authors expressed herein do not necessarily state or reflect those of the United States Government or any agency thereof. 


\section{DISCLAIMER}

Portions of this document may be illegible in electronic image products. Images are produced from the best available original document. 


\begin{abstract}
The oxidation of dimethyl ether (DME) is studied in low-pressure flames using new molecular beam mass spectrometer and laser diagnostics. Two 30.0-Torr, premixed DME/oxygen/argon flames are investigated with stoichiometries of 0.98 and 1.20. The height above burner profiles of nine stable species and two radicals are measured. These results are compared to the detailed chemical reaction mechanism of Curran and coworkers. Generally good agreement is found between the model and data. The largest discrepancies are found for the methyl radical profiles where the model predicts qualitatively different trends in the methyl concentration with stoichiometry than observed in the experiment.
\end{abstract}




\section{Introduction}

In recent years, environmental regulations in the United States, Europe, and Japan have been tightened for diesel engines emissions. Both particulate and NOx emissions standards have been reduced, and more restrictive statutes will take effect in coming years. Meeting these requirements with conventional diesel fuels is becoming increasingly difficult. Dimethyl ether (DME) has been proposed as an alternative diesel fuel that may be able to meet these new requirements. It is an attractive alternative because of its high cetane number, suggesting easy compression ignition. At the same time, it has the highest hydrogen to carbon ratio of any fuel except methane and no carbon-carbon bonds, elements that should reduce particulate emission.

Recent engine tests have shown that DME can reduce emissions from real engines. $[1,2]$ Furthermore, DME has been demonstrated to enhance the ignition of methanol-fueled diesel engines, significantly reducing the emission of unburned hydrocarbons[3]. To further enhance the performance of DME in combustion applications, a more detailed knowledge of its combustion chemistry is required. Several previous studies have investigated the thermal decomposition of DME[4-13]. The oxidation of DME has also been examined at room temperature and pressure in a number of laboratory studies.[1418] Ab initio studies have investigated the thermochemistry and kinetics of DME thermal decomposition and combustion initiation reactions $[19,20]$. Until recently, little work has focused on the high-temperature oxidation of DME characteristic of combustion. Recent work has led to the development of a detailed chemical kinetic model of DME combustion[21,22]. This reaction mechanism has been validated against jet-stirred 
reactor (JSR)[23], shock tube[24], flow reactor[22, 25], and atmospheric pressure, premixed flame data[26].

Low-pressure flame studies offer the opportunity to study the combustion of DME in detail, although the importance of three-body reactions is reduced in such flames compared to the high-pressure conditions in a diesel engine. Here we present lowpressure flame structure studies of two DME/oxygen/argon flames. Both molecular beam sampling mass spectrometer (MBMS) methods and laser-induced fluorescence (LIF) are used to probe the chemistry of these flames. Argon is chosen as the diluent, rather than nitrogen, to eliminate the NOx chemistry and thus simplify the modeling of these flames. The model calculations use the PREMIX one-dimensional, laminar flame code[27], which is based on the Sandia CHEMKIN kinetics code[28-30]. Model flame species profiles are calculated using the experimentally determined temperature profiles and the dimethyl ether oxidation mechanism of Curran et al[21].

\section{Experiment}

All experimental measurements are made in a new low-pressure flame, molecular beam mass spectrometer. The system includes both a single-photon, vacuum ultraviolet (VUV), photoionization, time-of-flight mass spectrometer (TOF-MS) and an electronimpact ionization (EI), quadrupole mass spectrometer (Q-MS). In addition, optical access to the flame chamber allows laser spectroscopic measurements to be made. The pertinent features of the system are described below. 


\section{Flame Chamber and Sampling System}

The low-pressure, premixed flame is supported on a stainless steel, water-cooled, $6.0-\mathrm{cm}$ diameter McKenna burner. The burner is housed in a $20-\mathrm{cm}$ diameter vacuum chamber. A computer controlled, commercial vacuum linear translation stage is used to vary the height of the burner relative to the space-fixed diagnostics. Gas is delivered to the burner through flow controllers calibrated against a NIST traceable mercury piston tube. The chamber pressure is measured with a capacitance manometer, and the desired chamber pressure is maintained to within 0.1 Torr by a servo controlled exhaust valve. The flame chamber has optical access ports centered on the mass spectrometer probe tip. These ports are separated from the chamber by small gate valves to facilitate optics changes without venting the entire system.

The molecular beam sampling mass spectrometer probe is formed from a quartz cone with a $40^{\circ}$ included angle for minimum flame perturbation, as described by Biordi et al.[31], and a $200 \mu \mathrm{m}$ opening at the tip. The probe flares to a $90^{\circ}$ included angle $35 \mathrm{~mm}$ from the tip to maximize pumping conductance. The total height of the probe is $78 \mathrm{~mm}$. It is attached to a water-cooled plate at the top of the flame chamber. Two $1500-1-\mathrm{s}^{-1}$ turbo molecular pumps remove the majority of the gas load from the probe. A 2-mm diameter, nickel skimmer samples the center of the molecular beam approximately 25 $\mathrm{mm}$ from the probe tip. Above the skimmer is the chamber containing the two mass spectrometers, which is pumped by two $550-1-\mathrm{s}^{-1}$ turbo molecular pumps. With 30.0 Torr in the flame chamber, the pressure between the quartz probe and nickel skimmer is 
approximately $10^{-4}$ Torr, and the pressure in mass spectrometer chamber is approximately $10^{-6}$ Torr.

\section{Mass Spectrometers}

The mass spectrometer chamber contains two instruments. The molecular beam first passes through the open ionization region of a Wiley-McLaren TOF-MS and then continues up to the ionization region of a quadrupole MS. Both systems have their analyzer axes perpendicular to the molecular beam axis.

The TOF-MS uses single photon, VUV photoionization and is similar in design to that of Cool and coworkers[32]. VUV photons are generated by either frequency tripling in $\mathrm{Xe}[33]$ or resonant, four-wave, sum-difference frequency mixing in $\mathrm{Kr}[34]$. Since frequency tripling is a relatively inefficient process, we use this method only for the generation of $118 \mathrm{~nm}(10.5 \mathrm{eV})$ light from the third harmonic of an Nd:YAG laser, which produces up to $180 \mathrm{~mJ} /$ pulse at $355 \mathrm{~nm}$ with $100 \mathrm{~Hz}$ repetition rate and a $2.5 \mathrm{~ns}$ pulse width. To produce tunable VUV in the range $8-10 \mathrm{eV}$, we use two optical parametric oscillators (OPO) pumped by separate Nd:YAG lasers with the specifications described above. The OPOs produce $10-20 \mathrm{~mJ}$ in the visible region. One is frequency doubled to produce $212-\mathrm{nm}$ light, which is two photon resonant with a $\mathrm{Kr}$ resonance at $106 \mathrm{~nm}$. The second OPO photon is used for difference frequency mixing from of the sum frequency. For both VUV generation methods, the light is focused by a $250-\mathrm{mm}$ focal length lens into a 25-mm diameter, stainless steel cell containing 10-50 Torr of rare gas. The resulting VUV light is recollimated with a $100-\mathrm{mm}$ focal length lithium fluoride lens and 
passed through a series of baffles within the MS chamber to eliminate forward scattered light, which otherwise produces photoelectrons, and thus EI signal, in the TOF-MS ionization region. Although the residual pump laser light also passes through the ionization region, no evidence has been found for multiphoton ionization. In the work described here only the tripling of 355-nm light is employed.

The flight tube of the TOF-MS is approximately $0.75 \mathrm{~m}$ and is differentially pumped by a $300-1-\mathrm{s}^{-1}$ turbo molecular pump to maintain a pressure of approximately $10^{-7}$ Torr during experiments. The detector is a commercial electron multiplier with copper berylliumoxide dynodes and provides a gain of about $10^{5}$ at typical operating voltages. Signals are collected simultaneously on a signal averaging digital oscilloscope (DO) and a multichannel scaler (MCS). The DO provides an accurate representation of high count rate signals, such as those from DME, while the MCS provides much better signal-to-noise ratio (SNR) for weaker signals that produce less than one ion per laser shot, typical of radicals. The TOF-MS system provides better than one amu mass resolution with a mass range of at least $300 \mathrm{amu}$.

The EI Q-MS system is based on a small, commercial, residual gas analyzer with variable EI energy. The system has one amu resolution with a range of $200 \mathrm{amu}$. For the experiments described here it is operated at an EI energy of $25 \mathrm{eV}$. Known cold flows of stable gases are used to calibrate the absolute response of the molecular beam sampling, Q-MS system. 


\section{Laser-Induced Fluorescence System}

For the present studies, we use $\mathrm{OH}$ laser induce fluorescence (LIF) to measure the flame temperature and to measure $\mathrm{OH}$ number densities in the flame. The system is similar to that used in the previous studies of Mcllroy[35] for this purpose. Briefly, we pump OH A-X $(0,0)$ and monitor total fluorescence through a solar blind photomultiplier tube (PMT). A pulsed, visible dye laser with $0.07 \mathrm{~cm}^{-1}$ resolution, $20 \mathrm{~Hz}$ repetition rate, and $2.5 \mathrm{~ns}$ pulse width is frequency doubled to produce the required 306-nm light. The probe intensity is limited to $<10 \mu \mathrm{J}$ to avoid saturating the transitions. A $412-\mathrm{mm}$ focal length lens brings the laser beam to a loose focus, $\sim 100 \mu \mathrm{m}$, at a distance of $3 \mathrm{~mm}$ below the probe tip. Fluorescence is imaged through a slit $\sim 1 \mathrm{~mm}$ high by $10 \mathrm{~mm}$ wide to reject scattered light from the quartz probe and limit the viewing region to the most homogeneous, center portion of the burner. The fluorescence lifetime at the peak of each transition is measured directly, and LIF signals are corrected for laser absorption through the flame, laser power fluctuations, and quenching variations. The excitation laser energy is kept low, $<200 \mathrm{~nJ}$, to avoid saturating the transitions, and the PMT gain is optimized to produce a linear response over the expected range of signals. $\mathrm{OH}$ concentration profiles as a function of height above the burner are also measured using this system. The LIF signal is calibrated by measuring the direct absorption of the probe beam in the post flame gases. Absorption is converted to concentration using the Einstein A coefficients of Luque and Crosley[36, 37] along with the measured temperature profile and fluorescence lifetimes. 


\section{Results}

We present temperature and species profiles for two 30.0-Torr (4.00 kPa) DME/ $\mathrm{O}_{2} / \mathrm{Ar}$ flames, a near stoichiometric flame $(\phi=0.98)$ and a fuel rich flame $(\phi=1.20)$. The flow rates are listed in Table I. In Figure 1, we show the temperature profiles for these two flames based on OH LIF temperature measurements and Ar thermal expansion as measured by the Q-MS system. Since Ar is unreactive, the change in the observed Ar signal with height above burner must come from either thermal expansion or dilution (or concentration) due to a chemically driven change in the gas composition. We can correct for the latter change in the mole fraction of Ar since the Q-MS system detects $>98 \%$ of the total species in the flame. We then scale the reciprocal of the corrected Ar signal to match the post flame LIF temperature measurements. As Figure 1 shows, the agreement between the LIF and thermal expansion data is good, and addition of the thermal expansion data enhances the fidelity of the empirical fit to the temperature data used in the model calculations. As expected, the rich flame stands further off the burner and has a higher ultimate temperature.

Figure 2 shows the mole fraction profiles of the major stable species detected by the QMS system for both flames, along with the predicted profiles from the model. All of the probe sampling data for the $\phi=0.98$ and 1.20 flames has been empirically shifted 0.07 and $0.13 \mathrm{~cm}$ respectively to account for probe shifting of the profiles. Figure 3 shows the minor stable species detected with the Q-MS system and the $\mathrm{OH}$ radical profile determined from LIF measurements. The Q-MS data are shifted, but the LIF data are not since they are not sampled through the probe. Figure 4 displays the $\mathrm{CH}_{3}$ radical profiles 
measured by VUV photoionization, TOF-MS. An absolute calibration of the signal is not readily available; thus the data are scaled to reproduce the peak mole fraction in the $\phi=0.98$ flame.

All of the Q-MS data, except that for formaldehyde $\left(\mathrm{CH}_{2} \mathrm{O}\right)$, are calibrated using known cold flows of analyte diluted in Ar. A well-characterized flow of $\mathrm{CH}_{2} \mathrm{O}$ is difficult to achieve. We calculate the calibration constant for $\mathrm{CH}_{2} \mathrm{O}$ from the measured $\mathrm{CO}$ calibration constant and the ratio of the $\mathrm{CO}$ and $\mathrm{CH}_{2} \mathrm{O}$ EI cross sections at $25 \mathrm{eV}$. CO is chosen since it has a similar mass to $\mathrm{CH}_{2} \mathrm{O}$ and thus similar transmission through the quadrupole mass filter. The CO EI cross section at $25 \mathrm{eV}$ is taken from the NIST compilation. We are unable to find $\mathrm{CH}_{2} \mathrm{O}$ EI cross section at $25 \mathrm{eV}$ in the literature. We calculate this value using the Binary-Encounter-Bethe (BEB) Model for EI cross sections[38], which is accurate to $5-20 \%$. The required molecular orbital properties are calculated at the MP2/6-31G++ level of theory using the Gaussian94 package[39]. The $\mathrm{CH}_{2} \mathrm{O}$ cross section at $25 \mathrm{eV}$ is found to be $1.67 \times 10^{-20} \mathrm{~m}^{2}$. 


\section{Discussion}

\section{$\underline{\text { Stable Species }}$}

As in the flow reactor studies, the model of Curran et al.[21] does a good job of reproducing the major stable species shown in Figure 2, DME, $\mathrm{O}_{2}, \mathrm{CO}, \mathrm{CO}_{2}, \mathrm{H}_{2} \mathrm{O}$, and $\mathrm{H}_{2}$. The most significant discrepancies observed are the early rise of $\mathrm{H}_{2} \mathrm{O}$ and $\mathrm{H}_{2}$ in the calculations compared to the experiment. There is also somewhat more $\mathrm{H}_{2}$ than predicted, particularly in the rich flame.

The minor species shown in Figure 3 display fair agreement between the model and data. The shape and magnitude of the formaldehyde peak are well produced within the accuracy of the calibration data, $\sim 10 \%$. The experimental methane mole fraction profile peaks further from the burner and displays a different shape than the model predicts. The model also over predicts the methane mole fraction, although larger discrepancies for methane have been observed in the lean flow reactor studies. The predicted and measured acetylene $\left(\mathrm{C}_{2} \mathrm{H}_{2}\right)$ profile shapes are in good agreement, but the magnitude of the experimental data is significantly higher than that predicted.

\section{Hydroxyl and Methyl Radicals}

The post flame concentration of the $\mathrm{OH}$ radical is well predicted by the model for the near stoichiometric flame. For $\phi=1.20$, the data fall below the model prediction in the post flame gases. However, the accuracy of the LIF data is approximately $\pm 10 \%$, limited primarily by the accuracy of the laser absorption measurement used for calibration. Thus 
the model lies just within the error bars of the $\phi=1.20$ data in the post flame zone. Further measurements will be required to determine whether this difference is significant. However, in both flames the model predicts a later rise in the $\mathrm{OH}$ concentration than shown in the data. This difference is outside the error limits of the data. The model predicts that $\mathrm{OH}$ is produced in the flame primarily by the four reactions:

$$
\begin{aligned}
& \mathrm{H}+\mathrm{O}_{2} \rightarrow \mathrm{O}+\mathrm{OH} \\
& \mathrm{CH}_{3}+\mathrm{O}_{2} \rightarrow \mathrm{CH}_{2} \mathrm{O}+\mathrm{OH} \\
& \mathrm{O}+\mathrm{H}_{2} \rightarrow \mathrm{H}+\mathrm{OH} \\
& \mathrm{CH}_{3} \mathrm{OCH}_{3}+\mathrm{O} \rightarrow \mathrm{CH}_{3} \mathrm{OCH}_{2}+\mathrm{OH}
\end{aligned}
$$

Of these reactions, the last has the least well determined rate. However, it seems unlikely that errors in this reaction alone could account for the discrepancy, particularly since the $\mathrm{DME}\left(\mathrm{CH}_{3} \mathrm{OCH}_{3}\right)$ is essentially gone in the region of largest difference. The primary $\mathrm{OH}$ destruction reactions predicted by the model are:

$$
\begin{gathered}
\mathrm{OH}+\mathrm{H}_{2} \rightarrow \mathrm{H}+\mathrm{H}_{2} \mathrm{O} \\
\mathrm{CH}_{2} \mathrm{O}+\mathrm{OH} \rightarrow \mathrm{HCO}+\mathrm{H}_{2} \mathrm{O} \\
\mathrm{CH}_{3} \mathrm{OCH}_{3}+\mathrm{OH} \rightarrow \mathrm{CH}_{3} \mathrm{OCH}_{2}+\mathrm{H}_{2} \mathrm{O} \\
\mathrm{CO}+\mathrm{OH} \rightarrow \mathrm{CO}_{2}+\mathrm{H}
\end{gathered}
$$

As with the formation reactions, the reaction rate of $\mathrm{OH}$ with $\mathrm{DME}$ is the least well determined, particularly at temperatures above $1000 \mathrm{~K}$. However, this reaction occurs much too early, at $x<0.2 \mathrm{~cm}$, in the flame to contribute to the observed discrepancy. The origin of this difference remains unclear. 
The methyl radical profiles shown in Figure 4 indicate that the model produces the wrong trend in concentration as a function of stoichiometry. We find the methyl radical mole fraction reduced in the rich flame, whereas the model predicts an increase in concentration. Scherer et al.[40] made a similar observation in a study of methyl concentrations by cavity ringdown spectroscopy in low-pressure methane flames. With their absolute methyl concentration measurements, they found good agreement with the calculated methyl concentration for a stoichiometric flame, but a reduced concentration in a rich ( $\phi=1.5)$ flame, where the model predicts an increased concentration.

The model predicts that the predominate methyl reactions in the low-pressure flame are

$$
\begin{gathered}
\mathrm{CH}_{3} \mathrm{OCH}_{2} \rightarrow \mathrm{CH}_{2} \mathrm{O}+\mathrm{CH}_{3} \\
\mathrm{CH}_{3}+\mathrm{O} \rightarrow \mathrm{CH}_{2} \mathrm{O}+\mathrm{H} \\
\mathrm{CH}_{3}+\mathrm{CH}_{2} \mathrm{O} \rightarrow \mathrm{HCO}+\mathrm{CH}_{4} \\
\mathrm{CH}_{3}+\mathrm{H} \rightarrow \mathrm{CH}_{4} \\
\mathrm{CH}_{3} \mathrm{OCH}_{3} \rightarrow \mathrm{CH}_{3}+\mathrm{OCH}_{3} \\
2 \mathrm{CH}_{3} \rightarrow \mathrm{C}_{2} \mathrm{H}_{6}
\end{gathered}
$$

Methyl is formed primarily by the decomposition of methyl methoxy radical and DME, and destroyed by reaction with $\mathrm{O}, \mathrm{H}, \mathrm{CH}_{2} \mathrm{O}$, and $\mathrm{CH}_{3}$. Experimental evidence suggests that the methyl formation reactions are approximately correct. The experimental disappearance of DME is well reproduced by the model, and the primary mechanisms for DME removal are hydrogen abstraction to form methyl methoxy radical and thermal decomposition. Since the primary loss of methyl methoxy is to form methyl, then the 
correct prediction of DME loss should be a good indicator of the correct prediction of methyl formation.

The methyl loss mechanisms shown above produce primarily formaldehyde and methane. The experimental formaldehyde profile is well reproduced by the model. Somewhat larger discrepancies are noted for methane, particularly in the rich flame, but the magnitude and sign of this difference does not correspond to the rich flame methyl discrepancy. Methyl recombination to form ethane might be expected to play a larger role in rich flame methyl loss. Unfortunately, we cannot directly observe ethane in our current experiments because of interference from formaldehyde at mass 30 . However, this reaction as been studied in great detail, and it seems unlikely that an error in its rate could account for the over prediction of methyl by the model in the rich flame.[41] Since fuel rich flames will certainly produce more methyl, it is most likely that the discrepancy between the model and experiment is due to additional loss, unaccounted for channels that are specific to rich.

\section{Conclusion}

A new molecular beam mass spectrometer instrument has been used to characterize two low-pressure dimethylether/oxygen/argon flames with stoichiometries of 0.98 and 1.20. Height above burner profiles for a number of stable species and the radicals $\mathrm{OH}$ and $\mathrm{CH}_{3}$ are reported. We compare these data to model calculations using the mechanism of Curran and coworkers[21]. Generally good agreement is found between the measurements and the model predictions. The largest discrepancies are found for the 
radicals, particularly $\mathrm{CH}_{3}$. The model predicts a qualitatively different trend for the $\mathrm{CH}_{3}$ mole fraction with increasing stoichiometry than that observed. We note that similar discrepancies in methyl concentrations have been observed previously in rich, lowpressure methane flames. Further measurements of more species and of flames covering a wider range of stoichiometries will be needed to provide further insight into these differences. 


\section{References}

1. Rouhi, A. M., Chemical and Engineering News, vol 29, 1995, p 37.

2. Brooks, R., WARD's Engine and Vehicle Update , 1995, p 3.

3. Green, C. J., Cockshutt, N. A., and King, L., Society of Automotive Engineers SAE-902155.

4. Benson, S. W., J. Chem. Phys. 25:27-31 (1956).

5. Benson, S. W., and Jain, D. V. S., J. Chem. Phys. 31:1008-1017 (1959).

6. Anderson, K. H., and Benson, S. W., J. Chem. Phys. 36:2320-2323 (1962).

7. McKenney, D. J., and Laidler, K. J., Can. J. Chem. 41:1984-1992 (1963).

8. McKenney, D. J., Wojciechowski, B. W., and Laidler, K. J., Can. J. Chem. 41:1993-2008 (1963).

9. McKenney, D. J., and Laidler, K. J., Can. J. Chem. 41:2009-2019 (1963).

10. Pacey, P. D., Can. J. Chem. 53:2742-2747 (1975).

11. Aronowitz, D., and Naegeli, D., Int. J. Chem. Kinet. 9:471-479 (1977).

12. Held, A. M., Manthorne, K. C., Pacey, P. D., and Reinholdt, H. P., Can. J. Chem. $55: 4128-4134$ (1977).

13. Manthorne, K. C., and Pacey, P. D., Can. J. Chem. 56:1307-1310 (1978).

14. Lapar, S. M., Wallington, T. J., Richert, J. F. O., and Ball, J. C., Int. J. Chem. Kinet. 22:1257-1269 (1990).

15. Wallington, T. J., Hurley, M. D., and C., B. J., Chem. Phys. Lett. 211:41-47 (1993). 
16. Jenkin, M. E., D., H. G., Wallington, T. J., Hurley, M. D., Ball, J. C., Nielsen, O. J., and Ellermann, T., J. Phys. Chem. 97:11712-11723 (1993).

17. Langer, S., Ljungstrom, E., Ellermann, T., Nielsen, O. J., and Sehested, J., Chem. Phys. Lett. 240:53-56 (1995).

18. Sehested, J., Mogelberg, T., Wallington, T. J., Kaiser, E. W., and Nielsen, O. J., J. Phys. Chem. 100:17218-17225 (1996).

19. Good, D. A., and Francisco, J. S., Chem. Phys. Lett. 266:512-514 (1997).

20. Nash, J. J., and Francisco, J. S., J. Phys. Chem. A 102:236-241 (1998).

21. Curran, H. J., Pitz, W. J., Westbrook, C. K., Dagaut, P., Boettner, J. C., and Cathonnet, M., Int. J. Chem. Kinet. 30:229-241 (1998).

22. Fischer, S. L., Dryer, F. L., and Curran, H. J., Int. J. Chem. Kinet. in press(2000).

23. Dagaut, P., Boettner, J.-C., and Cathonnet, M., Twenty-Sixth Symposium (International) on Combustion, The Combustion Institute, Pittsburgh, 1996, pp. $627-632$.

24. Pfahl, U., Fiewger, K., and Adomeit, G., Twenty-Sixth Symposium (International) on Combustion, The Combustion Institute, Pittsburgh, 1996, pp. 781-789.

25. Curran, H. J., Fischer, S. L., and Dryer, F. L., Int. J. Chem. Kinet. submitted.

26. Kaiser, E. W., Wallington, T. J., Hurley, M. D., Platz, J., Curran, H. J., Pitz, W. J., and Westbrook, C. K., J. Phys. Chem. submitted.

27. Kee, R. J., Grcar, J. F., Smooke, M. D., and Miller, J. A., "A Fortran program for modeling steady laminar one-dimensional flames," Sandia National Laboratories SAND85-8240.UC-4. 
28. Kee, R. J., Dixon-Lewis, G., Warnatz, J., Coltrin, M. E., and Miller, J. A., "A Fortran Computer Code Package for the Evaluation of Gas-Phase Multicomponent Transport Properties," Sandia National Laboratories SAND868246.UC-32.

29. Kee, R. J., Rupley, F. M., and Miller, J. A., "Chemkin II: A Fortran Chemical Kinetics Package for the Analysis of Gas-Phase Chemical Kinetics," Sandia National Laboratories SAND89-8009.UC-401.

30. Kee, R. J., Rupley, F. M., and Miller, J. A., "The Chemkin Thermodynamic Database," Sandia National Laboratories SAND87-8251B.UC-4.

31. Biordi, J. C., Lazzara, C. P., and Papp, J. F., Combust. Flame 23:73-82 (1974).

32. Werner, J. H., and Cool, T. A., Chem. Phys. Lett. 275:278-282 (1997).

33. Hilbig, R., and Wallenstein, R., IEEE J. Quantum Electron. QE-17:1566-1573 (1981).

34. Marangos, J. P., Shen, N., Ma, H., Hutchinson, M. H. R., and Connerade, J. P., J. Op. Soc. Am. B 7:1254-1259 (1990).

35. Mcllroy, A., Israel J. Chem. 39:55-62 (1999).

36. Luque, J., and Crosley, D. R., J. Chem. Phys. 109:439-448 (1998).

37. Luque, J., and Crosley, D. R., Appl. Phys. B 63:91-98 (1996).

38. Kim, Y.-K., and Rudd, M. E., Phys. Rev. A 50:3954-3967 (1994).

39. Frisch, M. J., Trucks, G. W., Schlegel, H. B., Gill, P. M., Johnson, B. G., Robb, M. A., Cheeseman, J. R., Keith, T., Petersson, G. A., Montgomery, J. A., Raghavachari, K., Al-Laham, M. A., Zakrzewski, V. G., Ortiz, J. V., Foresman, J. B., Peng, C. Y., Ayala, P. Y., Chen, W., Wong, M. W., Andres, J. L., Replogle, E. 
S., Gomperts, R., Martin, R. L., Fox, D. J., Binkley, J. S., Defrees, D. J., Baker, J., Stewart, J. J. P., Head-Gordon, M., Gonzalez, C., and Pople, J. A., "Gaussian 94," Gaussian, 1995.

40. Scherer, J. J., Aniolek, K. W., Cernansky, N. P., and Rakestraw, D. J., J. Chem. Phys. 107:6196-6203 (1997).

41. Baulch, D. L., Cobos, C. J., Cox, R. A., Frank, P., Hayman, G., Just, T., Kerr, J. A., Murrells, T., Pilling, M. J., Troe, J., Walker, R. W., and Warnatz, J., Evaluated Kinetic Data for High Temperature Reactions. Supplement I, (1994). 


\section{Tables}

Table I: Flame conditions. $\mathrm{P}=30.0$ Torr $(4.00 \mathrm{kPa})$ for all flames.

\begin{tabular}{|l|l|l|l|l|}
\hline$\phi$ & $\mathrm{X}\left(\mathrm{CH}_{3} \mathrm{OCH}_{3}\right)$ & $\mathrm{X}\left(\mathrm{O}_{2}\right)$ & $\mathrm{X}(\mathrm{Ar})$ & $\begin{array}{c}\text { Flow rate } \\
\left(\mathrm{g} \mathrm{cm}^{-2} \mathrm{~s}^{-1}\right)\end{array}$ \\
\hline \hline 0.98 & 0.0797 & 0.243 & 0.676 & 0.00481 \\
\hline 1.20 & 0.0826 & 0.2072 & 0.7102 & 0.00468 \\
\hline
\end{tabular}




\section{Figures Captions}

Figure 1: Temperature profiles determined from OH LIF and Ar expansion measurements for 30.0 Torr dimethylether/oxygen/argon flames of stoichiometry 0.98 and 1.20 . The solid symbols are LIF measurements and the open symbols are Ar expansion measurements. The lines are fits through the data used as input for the model calculations.

Figure 2: Major stable species mole fraction measurements and model calculations for 30.0 Torr dimethylether/oxygen/argon flames of stoichiometry (a) 0.98 and (b) 1.20 .

Figure 3: Minor stable species and $\mathrm{OH}$ radical mole fraction measurements and model calculations for 30.0 Torr dimethylether/oxygen/argon flames of stoichiometry (a) 0.98 and (b) 1.20 .

Figure 4: Methyl radical measurements and model calculations for 30.0 Torr dimethylether/oxygen/argon flames of stoichiometry (a) 0.98 and (b) 1.20. The data are scaled to match the 0.98 peak mole fraction. 


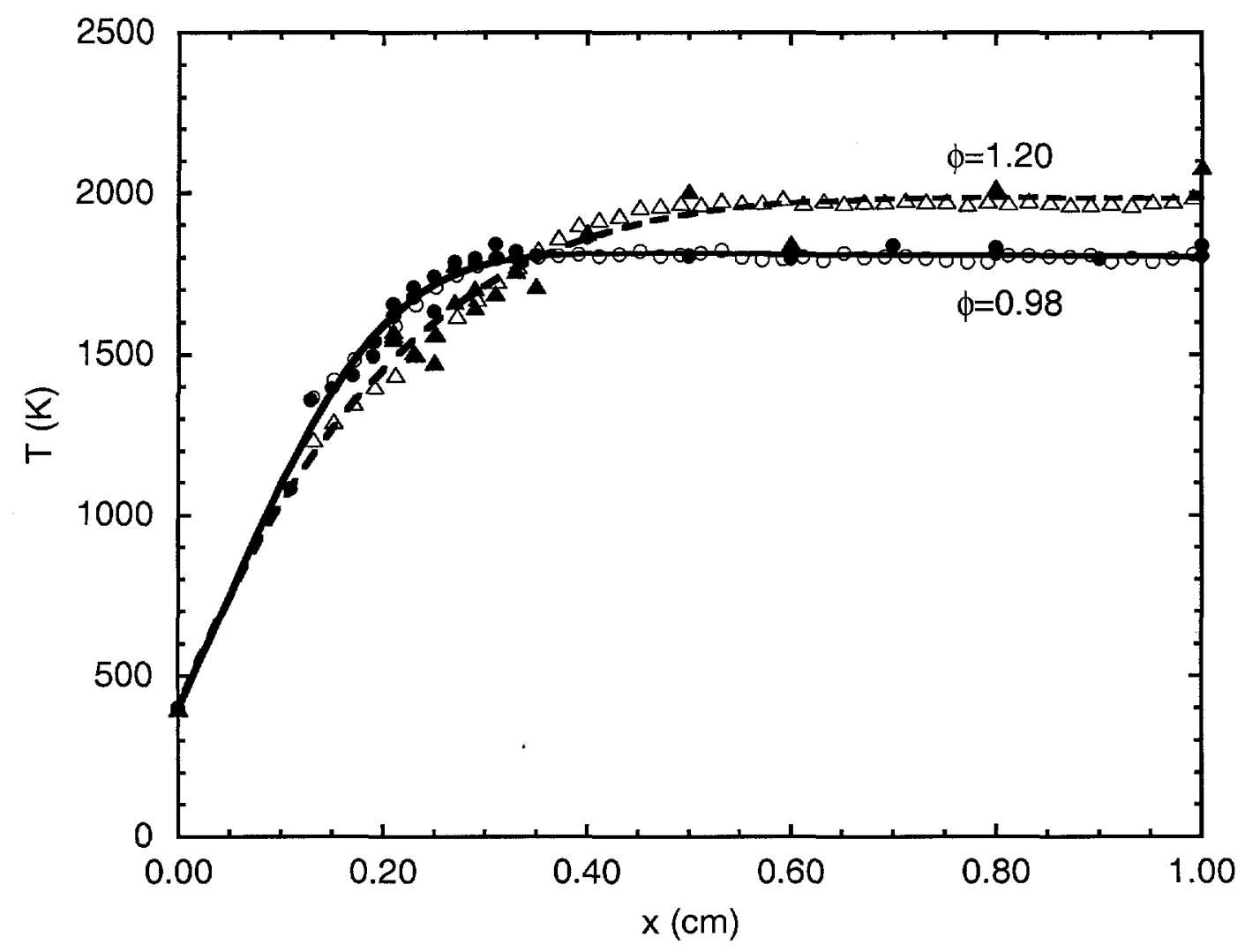

Figure 1 

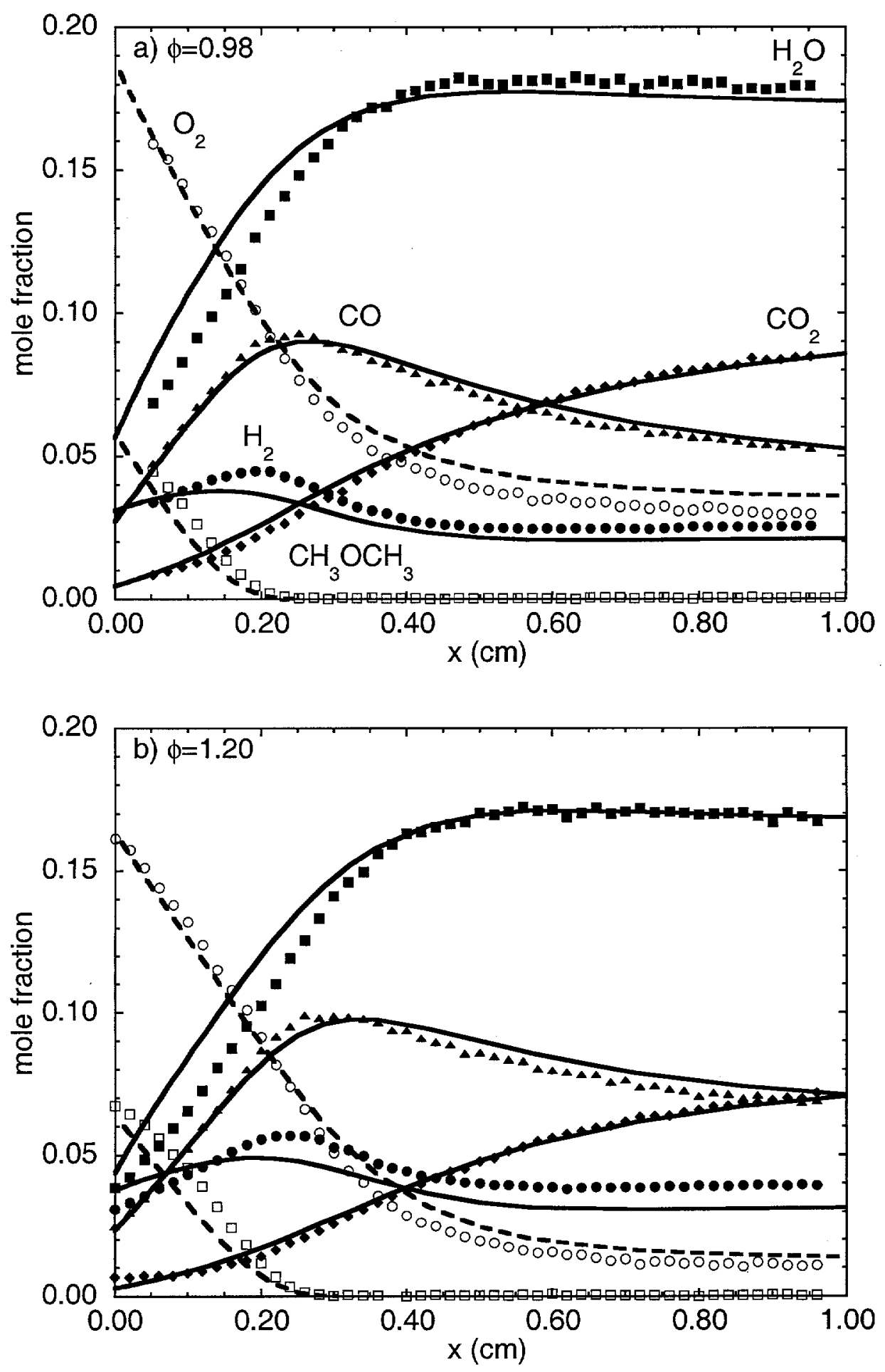

Figure 2 

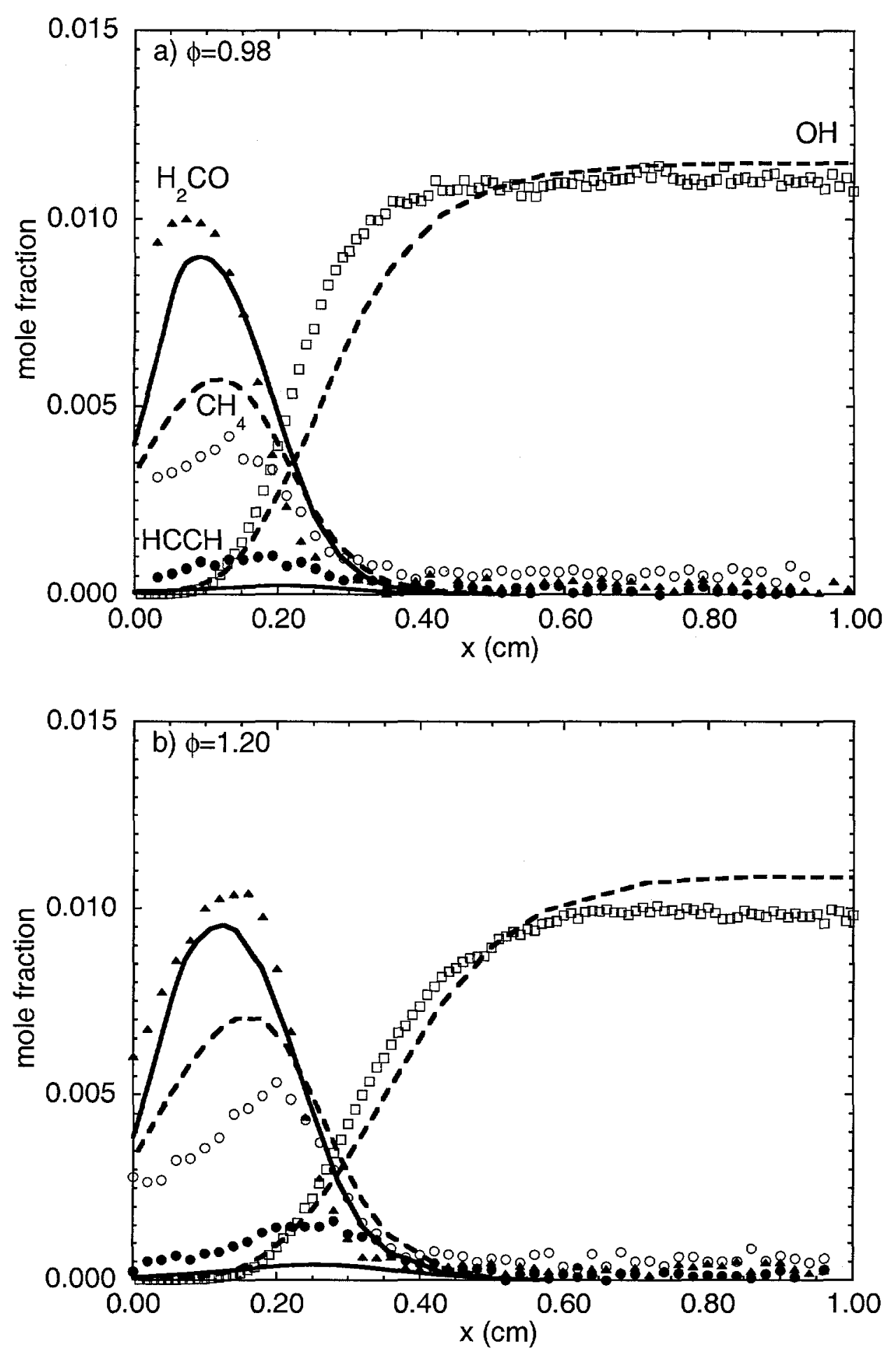

Figure 3 

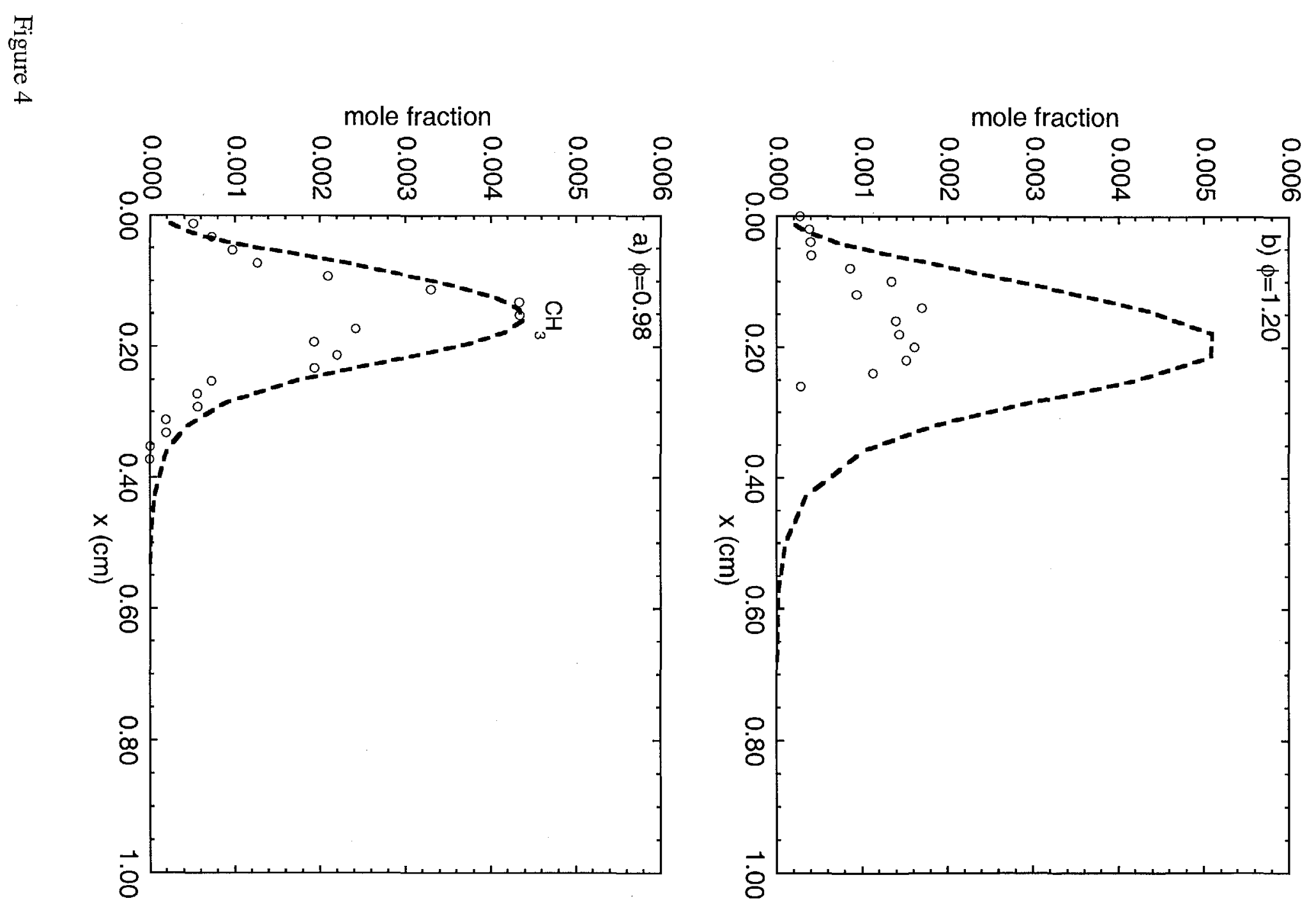